\title{
Exploring the impact of external shading system on cognitive task performance, alertness and visual comfort in a daylit workplace environment
}

Indoor and Built Environment 0(0) 1-14

(C) The Author(s) 2019

Article reuse guidelines:

sagepub.com/journals-

permissions

DOI: 10.1177/1420326X19864414 journals.sagepub.com/home/ibe

@SAGE

\author{
F Leccese ${ }^{1}$, G Salvadori ${ }^{1}$, M Öner ${ }^{1,2}$ (D) and \\ T Kazanasmaz ${ }^{2}$
}

\begin{abstract}
The authors examined the effect of external shading system on cognitive performance, alertness and visual comfort of visual display terminal (VDT) users under two realistic office lighting settings in this study. Daylight was the source of illumination being considered as the most significant and preferred one. A total of 26 participants performed visual and cognitive demanding tasks as well as providing subjective alertness, performance and visual evaluations in a full-scale mock-up VDT workstation. Two trials (with and without shading system) were executed during one experimental session. Results revealed that the use of a shading system improves the performance of a user on colournaming task requiring sustained attention, while no differential effects were observed on tasks involving other cognitive skills such as search velocity and vigilance. Within-subject performance differences were more pronounced during morning hours. Higher performance was reported in some cognitive tests when the subjective sensation of visual discomfort was lower.
\end{abstract}

\section{Keywords}

Daylighting, Cognitive task performance, Visual comfort, Alertness, Human building interaction

Accepted: 24 June 2019

\section{Introduction}

The visual display terminal (VDT) has been the most convenient tool in human-computer interaction since the 1980s. The use of VDTs, in particular office environments, has shown an immense increase with the wide availability of interaction and communication technologies (ICT). Nowadays, VDTs are being utilized for a variety of tasks by individuals on a daily basis. ${ }^{1-3}$ These tasks generally involve a range of activities which may require mental workload, decision-making, sustained attention and stimuli interpretation. ${ }^{4}$ The individual's successful fulfilment of the task is defined as cognitive task performance, which indicates the measurable outcome on a task. Measures of evaluating cognitive task performance can be divided into three meaningful main groups: performance (e.g. objectively measuring cognitive and visual capacity), subjective (e.g. self-report measures) and physiological (e.g. direct measurements continuously). The use of multiple measures, e.g. physiological arousal along with psychomotor vigilance test (PVT), is recommended for more reliable results by integrating the relative measures. ${ }^{5}$

At first glance, visual considerations can be considered first and foremost transmission path for

\footnotetext{
${ }^{1}$ School of Engineering, University of Pisa, Pisa, Italy ${ }^{2}$ Department of Architecture, İzmir Institute of Technology, Urla-İzmir, Turkey
}

\section{Corresponding author:}

Merve Öner, Largo Lucio Lazzarino, Pisa 56122, Italy.

Email: m.oner@studenti.unipi.it 
evaluating work output since the tasks are visual. Visual performance is known to increase as the intensity of illumination increases, but light intensity does not always bring positive impacts. ${ }^{6-8}$ It may, however, produce for example, glare that pose problems such as inability to perform a task or visual discomfort. Such circumstances in poorly lit environments may even force the necessity for poor sitting postures during VDT work. ${ }^{9,10}$ Distribution of light in work environments, e.g. in which way it is delivered and whether glare, reflections, or shadows are produced, is therefore strongly influential upon how the visual performance of individuals are manipulated. ${ }^{1,11}$

No VDT task, on the other hand, is solely visual, rather both demanding and complex. ${ }^{12}$ Lighting itself may not be able to create work output but influences the overall performance by impairing or facilitating the visual aspects of a task, and task performance is in fact a combination of visual, cognitive and motor components. ${ }^{8,13}$ Cognitive factors and visual functions, are known to be influenced via light for its alerting effects. ${ }^{4,6,7}$ Various studies have analysed the cognitive functions in VDT users under artificial lighting conditions. The influence of different illuminance values ${ }^{14-17}$ and light characteristics ${ }^{18-21}$ on cognitive performance has been well documented. Studies concerning the effect of daylighting on cognitive task performance in work environments however are still very scarce although daylight is recognized as the most preferred in working spaces ${ }^{22}$ for being more efficient in visual, physiological and psychological functions. ${ }^{23-25}$ Of the available literature that dealt with the impact of daylight on cognitive performance exclusively during VDT work, Rodriguez et al. ${ }^{26}$ measured attention and working memory in two different scenarios (a neutral environment and a glare demanding environment) in a rotatable experimental module where participants performed two different computer-based cognitive tasks. Each experimental session lasted about $30 \mathrm{~min}$ and data collection took 40 mornings with a total number of 32 participants. Comparison of results between daylit and sunlit scenarios revealed only statistically significant difference in reaction times (RTs) for incongruent stimuli during sustained attention test, in which higher performance was observed in daylit scenario compared to sunlit scenario. Similar finding was obtained in a study of Gou et al. ${ }^{27}$ as well, although the task was performed on paper. Results of experiments that were performed in morning hours indicated that the performance on a task measuring concentration and cognition decreased as the light intensity increased in the naturally-lit setting.

These findings suggest that, at least in some circumstances, higher illuminance might result in lower performance in some cognitive tasks requiring skills, e.g. attention and concentration, specifically during morning hours. These results are likely to be associated with particular demands of each cognitive task based on the time of the day. In other words, some specific tasks may require more illuminance than others whereas some tasks may be more sensitive to bright light. However, one should keep in mind that it remains incoherent and ambiguous to draw a generalizable conclusion from only a few studies.

Setting aside the struggles to find the optimal illuminance clues, more multidimensional approaches incorporating human factors need to be adopted, since presenting only illuminance data may be misleading ${ }^{28}$ while different physiological and psychological responses of individuals to luminous environment require continuous measurements from multiple analysis types. ${ }^{29}$ A well-known example is Baron's positive affect theory ${ }^{30}$ suggesting that preferred environmental lighting conditions induce a state of positive effect which in turn influence several aspects of cognition and behaviour. This theory was supported by the latter study of Baron and Thomley ${ }^{31}$ and another parallel study performed by $\mathrm{Knez},{ }^{20}$ which observed higher performance in the conditions that caused better effect, that is to say, more positive or less negative effect. Several studies have also shown that mood, ${ }^{32}$ gender, ${ }^{33,34}$ age $^{35}$ as well as time of day $^{36}$ and time of year ${ }^{37,38}$ are quite influential upon cognitive functions.

Together, illuminance effect on cognitive task performance particularly in daylit environments where lighting conditions are quite dynamic, is a multifaceted issue. The International Commission on Illumination $(\mathrm{CIE})^{39}$ suggests very sensitive experimental designs to identify the impact of lighting beyond the simple effects on visual performance, as a possible way to overcome such environmental and personal factors influencing performance of any task. The present study was, therefore, designed to extend the current knowledge of cognitive task performance depending on luminous environment and behavioural factors in two different ways. The first, through the exploration of the influence of an external shading system (i.e. the influence of exposure to different daylight levels) on the performance of a range of visual and cognitive demanding VDT tasks. The second, through the research of possible relationships between psychological and physiological factors such as subjective arousal and performance measures and cognitive task performance.

\section{Material and methods}

\section{Participants}

A total of 26 (17 male and 9 female) undergraduate and postgraduate students participated in the study. 
They were all healthy and had normal or corrected visual acuity (Vision test; www.essilor.com). The participants were between 20 and 30 years old $(\mathrm{M}=23$, $\mathrm{SD}=3.14$ ) and were using a computer at least $8 \mathrm{~h}$ every day. According to a validated light sensitivity test by Fortuin, ${ }^{40}$ people within this age range have the similar light sensitivity because of the ageing effect on the eyes. None were aware of the scope of the research and the expected outcomes of the study. Participants were asked to keep their sleep-wake schedule two days before the experimental session as similar as possible to their sleep routine on workdays $( \pm 30 \mathrm{~min})$ as stated in Munich Chronotype Questionnaire (MCTQ). ${ }^{41}$ So that, the possibility of confounding factors associated with general fatigue that may be confused with the expected influence of different illuminance levels during the experiment would be strongly reduced.

\section{Setting}

The experiments were performed at the Lighting and Acoustics Laboratory of the University of Pisa (School of Engineering), where a full-scale mock-up VDT workstation of $2.0 \times 2.0 \times 2.4 \mathrm{~m}$ was installed. Located on the top floor of a two-storey building, the mock-up was lit by 115 degrees southeast-oriented window, consisting of a double glass with a light transmission coefficient of 0.75 . There were no near exterior obstructions in the surroundings which reduced access to sunlight. In each experiment, the subject's visual field included the identical scenes consisting of a workstation, a non-reflecting wall-like façade felt, and the same ceiling mounted cladding. Figure 1 shows the plan and the section layout of the mock-up laboratory setting.

The workstation was equipped with an office chair, a desk $(1.4 \mathrm{~m}$ by $0.9 \mathrm{~m})$, and an Intel ${ }^{\circledR}$ Core $^{\mathrm{TM}}$ i5-7500 CPU @ 3.40 GHz 3.41 GHz desktop computer with Asus 2400 Brilliance 15.6" LCD monitor, whose display resolution was $1280 \times 1024$ pixels at a fresh rate of $60 \mathrm{~Hz}$. The desk was placed parallel to the windows and participants faced the glazing, so that the impact of changing daylighting conditions would be easily observed through the eye movements. Adjustments of the workstation including display height, working distance, angle, were made in accordance with EN ISO 9241-5:1998 and the VDT workstation design guidelines. ${ }^{3,10}$ Participants were allowed to choose their own sitting height provided that the viewing distance of around $60 \mathrm{~cm}$ for a sustained 30-min period was kept the same. The layout of the workstation remained the same throughout the whole experiment. To avoid potential distractions due to the luminance distribution surrounding the screen, surface properties were chosen in a way to ensure a pleasant environment which minimizes the risks of veiling reflections, annoying brightness etc. Vertical illuminance at the eye from all the glare sources was measured every $5 \mathrm{~s}$ by using the data logger Delta Ohm model HD2101.1 with the photometric probe LP 471 PHOT (general mismatch index $\mathrm{f}_{1}^{\prime}$ and deviation in directional response index $\mathrm{f}_{2}$, according to the international standard, ISO/CIE

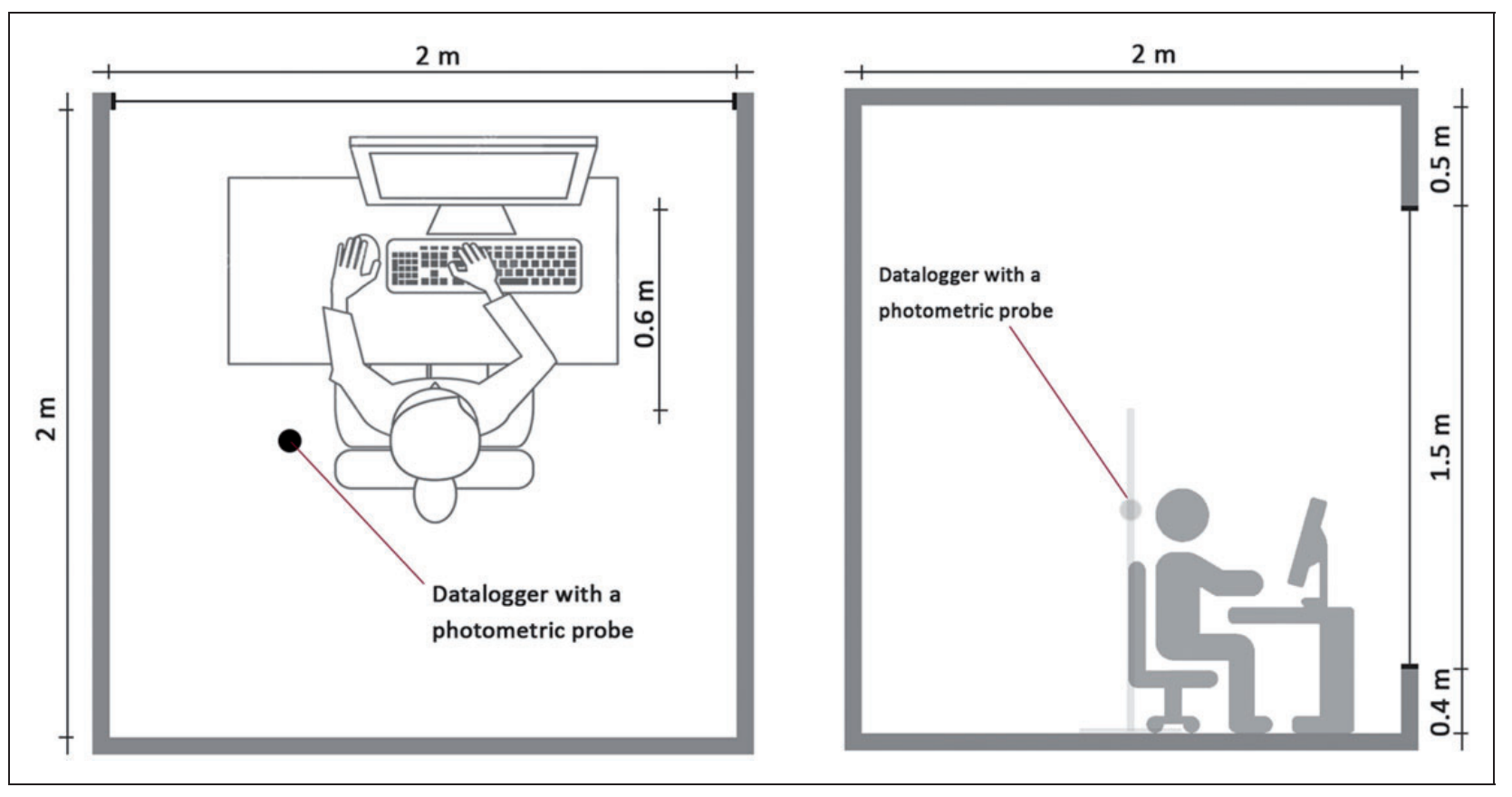

Figure 1. Plan and section layout of the mock-up laboratory setting. 
$19476: 2014,{ }^{42}$ lower than $6 \%$ and $3 \%$, respectively), which was placed on a tripod at the eye level. The device was properly calibrated and normalized prior to the study (calibration uncertainty lower than $4 \%$ ).

\section{Experimental design and procedure}

All experiments were consistently conducted between 10:00 am and 12:00 am or 03:00 pm and 05:00 pm for a period of 3 weeks (from 8 May to 11 June 2018), where an adequate amount of daylight was present inside the mock-up. During the experiment, participants were asked to perform a series of tasks including letter search, vigilance and sustained attention tests. The sequence of activities performed was not randomized but the stimuli in each task was randomly displayed (e.g. text/colour combinations in sustained attention test). The tasks were repeated twice for each participant, as two sessions of the experimental stage, one for each solar shading position (see Figure 2): (i) with the shading system completely inactive and (ii) with the shading system active, with the slats tilted $5^{\circ}$ downward to the exterior. The sequence of the shading positions was randomized to avoid any order effects occurring from the lighting conditions.

As the method was a repeated-measures design, short practice trials for each task were employed before the experiment began to minimize the risk of unwanted learning effects which lead to increase participants' efficiencies over time with their experience in earlier tests. The training session lasted about $5 \mathrm{~min}$ while participants familiarized with the procedure of the experimental setting and achieved some expertise on tasks for the adaptation time to the experimental setting. Extended version of the practiced tasks was used during the experimental study and one full session lasted approximately 30 -min consisting of two experimental sessions (see Figure 3).

Apart from the objective measures, subjective task performance (STP) questionnaires were filled in after

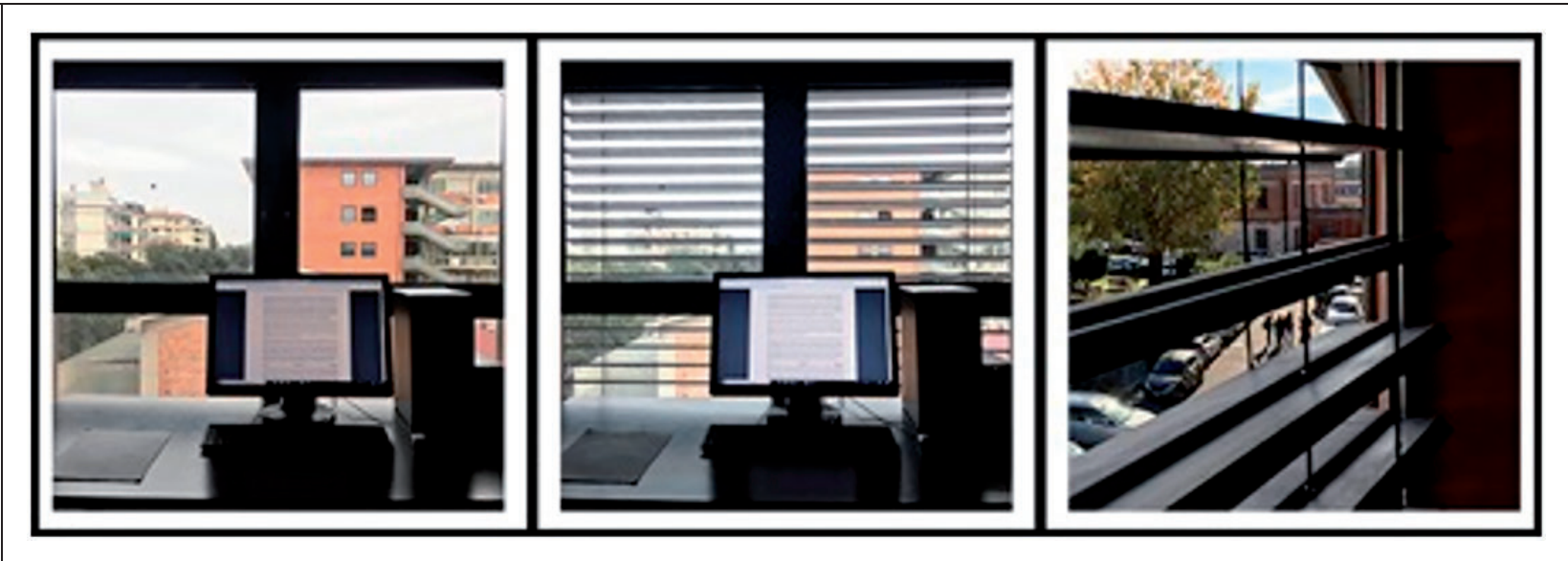

Figure 2. Experimental settings (left to right): shading system inactive, shading system active, focus on the tilted slats $\left(5^{\circ}\right.$ downward to the exterior).

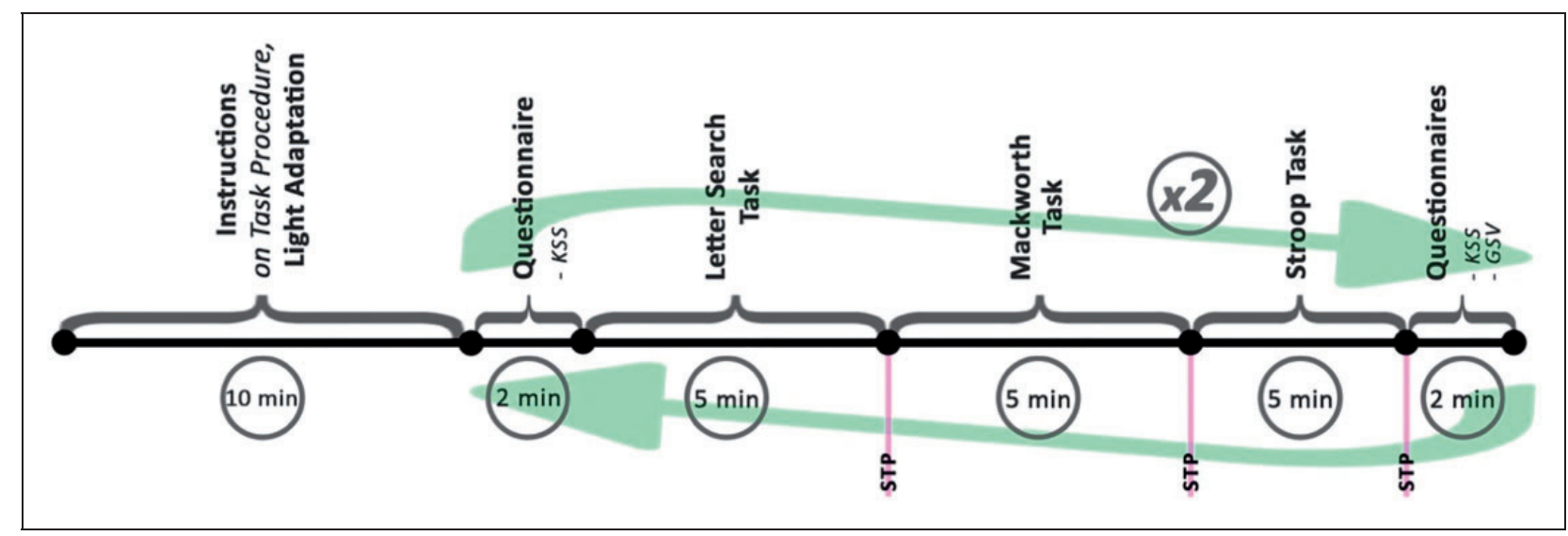

Figure 3. Time schedule of the experimental stage. 
each task, to explore participants' performance rating on the tasks. Subjective sleepiness (KSS) and the level of perceived visual discomfort (VAS) were assessed at the beginning and the end of each experimental session through an online set of questions. Finally, participants were asked to complete a glare sensation vote (GSV) scale to measure the level of perceived glare during the experiment.

\section{Dependent measures}

A multi-dimensional approach based on objective and subjective measures was adopted for exploring the impact of a solar shading strategy on the performance of various cognitive tasks during VDT use. Two groups of key variables were chosen for being the most related parameters to the performance and well-being of VDT users: (i) cognitive task performance (i.e.: search velocity (SV), vigilance, RT) and (ii) subjective assessments (i.e.: subjective alertness, STP, GSV).

Cognitive task performance. Cognitive efficiency was measured by three different tasks requiring SV, vigilance and sustained attention that involve typical aspects of regular VDT works. Search accuracy and character identification correspond to significant amount of typical VDT work.

Regarding these measures, an approximately 5 -minute letter search task in a variety of display settings was conducted. It consisted of 50 search displays with $5,10,15$, or 20 items. Participants were instructed to press to the space bar as fast as possible when they saw the letter $\mathrm{T}$ only if it was ordinary upright position and with orange colour. They were also told not to do anything until the next setting was displayed if no $\mathrm{T}$ was present. In this type of task, search time is expected to increase in parallel with the large numbers of items on the screen. SV (ms) of each search display (with 5, 10,15 or 20 items) was recorded as output measures.

Subsequently, participants were engaged in a Mackworth clock task, ${ }^{43,44}$ in which their vigilance was assessed. They were instructed to press the space bar immediately when the clock hand jumps more than normally while monitoring the clock hand move around. The test lasted $5 \mathrm{~min}$. The likelihood of an unusual jump of the clock hand was set to around $40 \%$. The score was calculated as the sum of missed and wrongly detected skips. It was used as an outcome variable.

Participants were then asked to respond to the STP questionnaire describing their self-assessment on vigilance test, and the last test was performed.

The Stroop test requires sustained attention and executive function to name the colour of the appeared word on screen. Participants were instructed to respond to the print colour (green, yellow, red, blue) of the displayed colour name (GREEN, YELLOW, RED, BLUE) and press to the associated button on the keyboard (e.g. 'G' for green, 'Y' for yellow, 'R' for red, 'B' for blue) as rapidly and correctly as possible. A semantic interference called 'Stroop effect' occurs once there is an incongruity between the colour and word (e.g. the word BLUE is shown in red colour), and it requires participants to respond with increased effort so that the natural tendency for reading the word name can be avoided, and instead the incongruent colour of the word written is able to be identified. ${ }^{45}$ This extra effort refers to either slower response times or decreased accuracy for incongruent trials when compared to congruent ones. ${ }^{46}$ Using PsyToolkit, ${ }^{47,48}$ a total of 50 trials were randomly displayed at the centre of the screen in 20-pt Arial font. The test took about 3-min and the RT to congruent and incongruent stimuli were used as measure in the analysis of the cognitive task performance.

Subjective alertness. Self-reported alertness was measured with the Karolinska Sleepiness Scale (KSS). ${ }^{49}$ The KSS is widely used to evaluate level of arousal. It consists of a 9-point Likert scale assessment of sleepiness with numbers from 1 to 9 having representations; for example, where 1 indicates 'extremely alert' and 9 stands for 'almost sleeping'. Subjective sleepiness level of participants was measured with a modified Italian version of KSS in each session. This was repeated twice for each setting (just prior to the letter search test and just after the Stroop test), for a total of two evaluations to determine whether there was any decrease or increase in the level of arousal when exposed to different light levels.

Subjective task performance. Participants were asked to assess their cognitive efficiency at the end of each task using a Visual Analogue Scale (VAS) adopted from Huiberts et al. ${ }^{50}$ The original English version of STP was translated into Italian in this study. It consisted of four questions with response options on a scale from 0 (not at all) to 100 (very much): how well participants thought they had performed on the task, how motivated they were to perform the task as well as possible, how well they could concentrate on the task and how much mental effort they had to put into the task. The Cronbach's alpha reliability measure for all items was between $\alpha=0.808$ and $\alpha=0.845$.

GSV. Subjective sensation of visual discomfort was examined at the end of each experimental session by using a GSV scale. This measurement employs a 4-point scale with response options from 
1 (imperceptible) to 4 (intolerable). It was originated from the study of Hopkinson ${ }^{51}$ and stands for the perceived glare sensation responded by participants.

\section{Statistical analysis}

\section{Analysis approach}

All the statistical analyses were performed using IBM SPSS statistics software (version 17.0). Before running the statistical analysis, all the variables were verified with a normality test to decide on which statistical analysis would be used. A Shapiro-Wilk test for normality was preferred due to the relatively small sample size of less than 30 . Based on results of normality tests, parametric tests were applied to normal data $(p>0.05)$ and non-parametric tests were applied to non-normally distributed data $(p<0.05)$. Due to the small sample size and a mainly non-normal data, a significance level of $p=0.1^{52,53}$ was adopted for the significance tests. Effect sizes were calculated since $p$-values might not be sensitive to effect sizes in such biased experimental groups as in the present study. Keeping these limitations in mind, in addition to $p$, the effect size $r$ was employed for analysing the significance of the data. The effect size (r) can be derived by equation $(1)^{54}$

$$
r=Z-\text { score } / N^{0.5}
$$

with $Z$-score the signed fractional number of standard deviation for the observed data and $\mathrm{N}$ the number of observations. According to Ferguson, ${ }^{55}$ obtained $r$ values indicate small $(r \geq 0.20)$, moderate $(r \geq 0.50)$ and strong $(r \geq 0.80)$ effect sizes.

A paired t-test analysis was used to compare selfreported level of arousal at the beginning and at the end of experimental sessions. To assess the statistical difference of the repeated measurements with non-normal data, Wilcoxon signed-rank test, non-parametric equivalent of paired t-test, was used. Kruskal-Wallis and Mann-
Whitney U-test was performed to compare results across different groups such as morning and afternoon. The bivariate nonparametric correlations were calculated by using Spearman's rho correlation test to determine the relationship between, e.g. objective parameters and subjective ratings.

\section{Results}

To check the normality of distribution for illuminance data in the case of shading-on and shading-off settings, Shapiro-Wilk normality test was applied. The W-test revealed data to be not normally distributed for shading-on ( $p=0.006$ ) but normally distributed for shadingoff setting $(p=0.403)$. Therefore, non-parametric equivalent of one-way analysis of variance, KruskalWallis was used to explore the relationship between received vertical illuminances in two shading settings. The result $\left(\chi^{2}=10.2, \quad d f=1, \quad p=0.001, \quad r=0.196\right)$ revealed a significant difference between received light levels with a small effect size. Further, when the overall data was grouped by the time of the day, the shading settings had a statistically significant effect on vertical illuminance both in the morning $\left(\chi^{2}=4.278, d f=1\right.$, $p=0.039, r=0.194)$ and more pronouncedly in the afternoon with a higher effect size $\left(\chi^{2}=6.939, d f=1\right.$, $p=0.008, r=0.231$ ).

Based on the statistically significant difference between shading-on and shading-off settings, hereafter in the following sections of this paper, the variables referred to the different settings (shading-on and shading-off) are indicated as $\mathrm{S}_{\mathrm{ON}}$ and $\mathrm{S}_{\mathrm{OFF}}$, respectively. Descriptive statistical values for the photometric data measured throughout the experimental sessions are provided in Table 1.

Subjective glare sensation. Firstly, the MannWhitney U test was conducted to evaluate the relationship between GSV scores and the shading setting in a broad perspective. Results indicated that when the

Table 1. Descriptive statistical values for the illuminance data.

\begin{tabular}{|c|c|c|c|c|c|}
\hline & \multicolumn{5}{|c|}{ Vertical illuminance at eye level (lx) } \\
\hline & Mean & SD & Median & Minimum & Maximum \\
\hline \multicolumn{6}{|l|}{$\mathrm{S}_{\mathrm{OFF}}$} \\
\hline Overall & 1296 & 602 & 1118 & 224 & 2646 \\
\hline Morning & 1643 & 632 & 1661 & 426 & 2646 \\
\hline Afternoon & 1041 & 404 & 1082 & 224 & 1677 \\
\hline \multicolumn{6}{|l|}{$\mathrm{S}_{\mathrm{ON}}$} \\
\hline Overall & 780 & 504 & 649 & 185 & 2033 \\
\hline Morning & 969 & 667 & 671 & 282 & 2033 \\
\hline Afternoon & 642 & 347 & 598 & 185 & 1425 \\
\hline
\end{tabular}

$\mathrm{S}_{\mathrm{ON}}$ : shading-on; $\mathrm{S}_{\mathrm{OFF}}$ shading-off. 
shading system was active, the self-reported glare rates were found statistically significantly lower $(p=0.013$, $Z=-2.494, r=0.345$ ).

Secondly, Wilcoxon signed-rank test was conducted to explore the overall within-subject variations in response to two different shading settings. Based on the previous research, the glare sensation was predicted to show a tendency to increase when the shading system was not active. Results provided evidence that differences in the level of glare perception between two experimental stages were statistically significant $(p=0.018, Z=-2.357, r=0.462)$. When the shading system was active, participants rated the experimental space around $29 \%$ less disturbing.

Thirdly, to explore the effect of time of day on the degree of glare acceptance, a Mann-Whitney U test was employed by grouping the data in two, as morning and afternoon. The results, like those obtained in a previous study of Kent et al., ${ }^{56}$ showed statistically significant effect of the time of day on glare sensation. Experienced visual discomfort was more pronounced during the morning ( $p_{\text {morning }}=0.038, Z=-2.076$, $r=0.442)$ compared to afternoon $\left(p_{\text {afternoon }}=0.093\right.$, $Z=-1.680, r=0.306$ ).

In Figure 4, the perceived glare is plotted in $\mathrm{S}_{\mathrm{OFF}}$ and $\mathrm{S}_{\mathrm{ON}}$ settings for morning and afternoon groups, separately. Y-axis shows the number of participants that rated the visual environment as: 'Imperceptible' or 'Noticeable' or 'Disturbing' or 'Intolerable' on the GSV scale. This figure indicates that the positive effect of the use of shading system is more visible giving that participants experienced more visual discomfort during morning hours when the shading system was not active, whereas we see a less pronounced effect of the shading in afternoon data.

Effect size of settings for each time factor was also calculated using the procedure as described for MannWhitney U test. Descriptive statistics and inferential analyses of GSV ratings are provided in Table 2, showing that the $r$ and $p$-value are not necessarily consistent.

Cognitive task performance. Since experiments were repeated twice in $\mathrm{S}_{\mathrm{ON}}$ and $\mathrm{S}_{\mathrm{OFF}}$ settings, a withinsubject design analysis was conducted to investigate

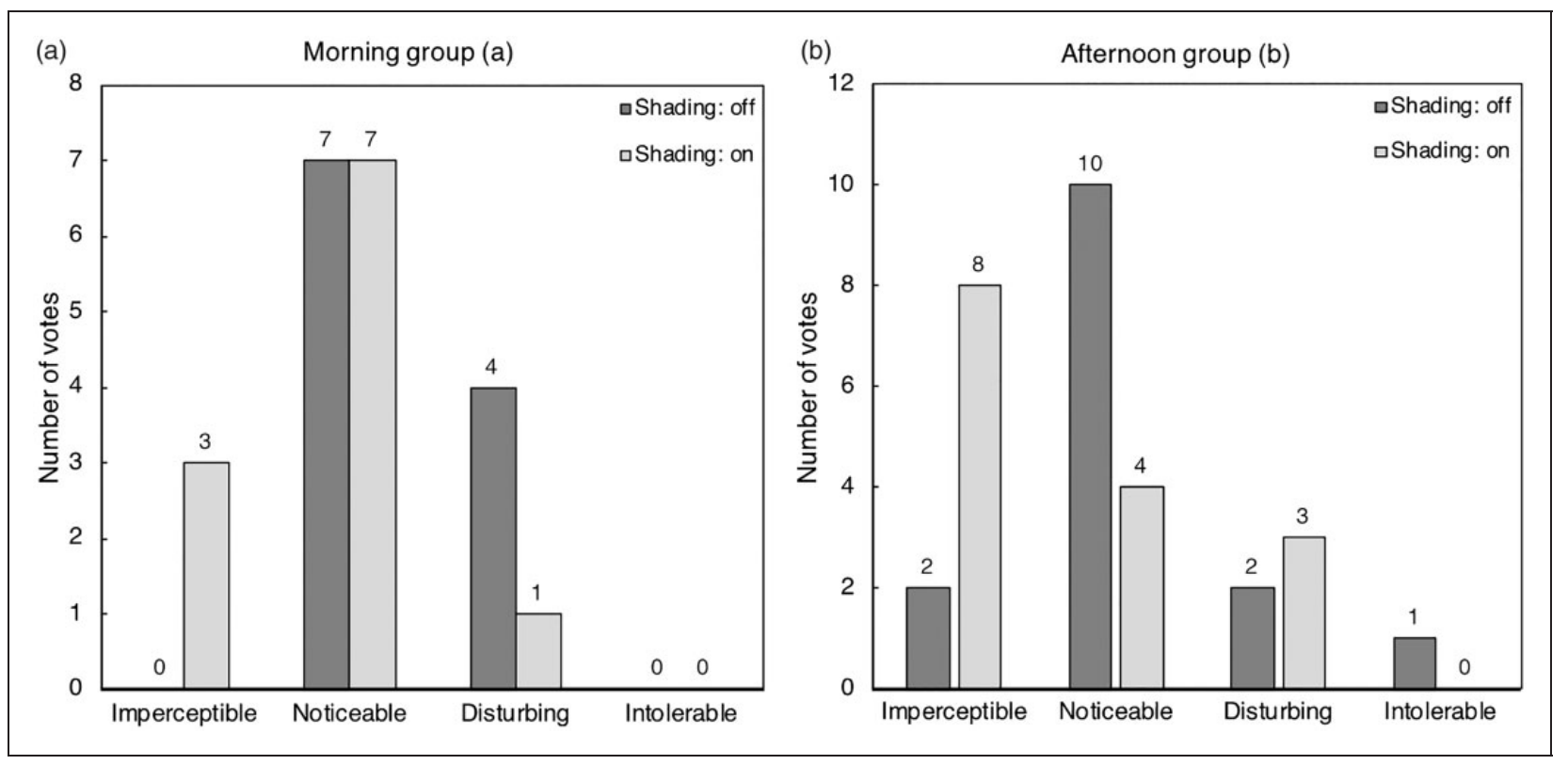

Figure 4. Bar charts of the perceived glare obtained by the participants for (a) morning and (b) afternoon group in the cases of $\mathrm{S}_{\mathrm{ON}}$ and $\mathrm{S}_{\mathrm{OFF}}$.

Table 2. Descriptive and inferential statistics obtained from the glare sensation votes.

\begin{tabular}{|c|c|c|c|c|c|c|}
\hline Shading setting & $\operatorname{Mean}_{\mathrm{ON}}(\mathrm{SD})$ & $\operatorname{Mean}_{\mathrm{OFF}}(\mathrm{SD})$ & $\Delta \mathrm{M}$ & $Z$-score & Effect size $(r)$ & $p$ \\
\hline $\mathrm{S}_{\mathrm{ON}}$ vs. $\mathrm{S}_{\mathrm{OFF}}$ (overall) & $1.73(0.724)$ & $2.23(0.652)$ & 0.50 & -2.494 & 0.345 & 0.013 \\
\hline $\mathrm{S}_{\mathrm{ON}}$ vs. $\mathrm{S}_{\mathrm{OFF}}$ (morning) & $1.50(0.512)$ & $2.09(0.610)$ & 0.59 & -2.076 & 0.442 & 0.038 \\
\hline $\mathrm{S}_{\mathrm{ON}}$ vs. $\mathrm{S}_{\mathrm{OFF}}$ (afternoon) & $1.66(0.509)$ & $1.90(0.803)$ & 0.24 & -1.608 & 0.306 & 0.093 \\
\hline
\end{tabular}

$\mathrm{S}_{\mathrm{ON}}$ : shading-on; $\mathrm{S}_{\mathrm{OFF}}$ shading-off. 
whether an effect of shading system could be detected on cognitive performance, in different tasks that require a basic set of skills during VDT work. Outcome performance factors for letter search, vigilance and sustained attention tasks were specified as $\mathrm{SV}$, error rate (ER) and response time, respectively. Table 3 shows the descriptive statistics from the analysis of the cognitive task performance of participants in two different shading settings. For each analysed performance factor, Table 3 shows means and standard deviations in two shading settings and the statistical significance $(p)$, effect size $(r)$ and Z-score obtained from Wilcoxon signed-rank test. From the data only a significant decrease in $\mathrm{RT}$ of congruent trials was observed during sustained attention test in $\mathrm{S}_{\mathrm{ON}}$ setting $(p=0.096)$. Not statistically significantly, but still, there were also decrease in RT of incongruent trials with a rate of $7 \%$ and decrease in ER in vigilance test with a rate of $18 \%$ in $\mathrm{S}_{\mathrm{ON}}$ setting. Oppositely, $\mathrm{SV}$ in $\mathrm{S}_{\mathrm{ON}}$ setting was greater in all stimuli including 5, 10, 15, 20 items when compared to $\mathrm{S}_{\mathrm{OFF}}$ setting.

To understand whether the time of day had an influence on the relationship between cognitive efficiency and shading settings, a Mann-Whitney $U$ tests was employed, comparing the test results of each group (morning and afternoon) separately. No significant difference was found between morning (11 participants) and afternoon (15 participants) groups ( $p>0.1$ for all variables). In addition, another Wilcoxon signed-rank test was employed to test within-subject differences both in the morning and the afternoon groups. Shading setting, the within-subject variable, had only significant effect on the RT of congruent trials during sustained attention test in the morning group. Participants gave faster responses in $\mathrm{S}_{\mathrm{ON}}$ setting $(p=0.062, Z=-1.867, r=0.398)$.

Interestingly, when the potential influence of trial order on objective cognitive performance was analysed, the data revealed that learning effect was also pronounced over time in terms of RTs of congruent and incongruent trials in sustained attention test $\left(p_{\text {congruent }}=0.092, p_{\text {incongruent }}=0.096\right)$. This practice effect was also supported by the questionnaire results indicating that the mental effort spent on the secondary sustained attention test was around 15\% lower than the first trial, which may suggest that participants needed less mental effort as being more efficient over time by practice. In contrast, the overall results did not show a systematic learning effect. For example, no statistically significant differences were observed between trial order and letter search or vigilance tasks. This also in line with earlier research indicating that learning effect is a complicated matter occurring nonsystematically among different type of tasks, ${ }^{57}$ which would appear to be consistent with results, indicating a learning effect for sustained attention and letter search, although not for vigilance. Then, what these results do present is that such variations across the different task types can be explained by the weakness of the learning effect or the fact that some task efficiencies may be more proper to be improved by practice than others.

Subjective task performance. After each task, subjective task performance (STP) was assessed by the participants on a scale from 0 to 100 . The questionnaire consisted of four questions measuring separately overall success, motivation, concentration and mental effort, respectively. No statistically significant differences were observed between mean STP values in $\mathrm{S}_{\mathrm{ON}}$ and $\mathrm{S}_{\mathrm{OFF}}$ settings $\left(p>0.1\right.$ for all variables). In $\mathrm{S}_{\mathrm{OFF}}$ setting, higher illuminance appeared to promote slightly greater motivation, concentration and mental effort levels during all the tasks except vigilance test (see Figure 5). Considering Figure 5, the subjective selfreports of performance indicators increased or remained the same as the illuminance was increased. The main and most visible inference from STP scores may be that the participants rated their success and effort spent

Table 3. Within-subject cognitive task performance comparisons in $\mathrm{S}_{\mathrm{ON}}$ and $\mathrm{S}_{\mathrm{OFF}}$ settings.

\begin{tabular}{|c|c|c|c|c|c|c|c|}
\hline \multirow[b]{2}{*}{ Task types } & \multicolumn{2}{|l|}{$\mathrm{S}_{\mathrm{ON}}$} & \multicolumn{2}{|l|}{$\mathrm{S}_{\mathrm{OFF}}$} & \multicolumn{3}{|c|}{ Within-subjects statistics $\left(\mathrm{S}_{\mathrm{OFF}}-\mathrm{S}_{\mathrm{ON}}\right)$} \\
\hline & Mean & SD & Mean & SD & $Z$-score & $\begin{array}{l}\text { Asymp. Sig. } \\
\text { (2-tailed) }\end{array}$ & $\begin{array}{l}\text { Effect } \\
\text { size }(r)\end{array}$ \\
\hline SV $(\mathrm{ms})$ - with 5 items & 808.53 & 452.32 & 728.65 & 107.07 & -0.267 & 0.790 & 0.005 \\
\hline SV $(\mathrm{ms})$ - with 10 items & 930.34 & 341.08 & 869.42 & 187.10 & -0.724 & 0.469 & 0.141 \\
\hline SV (ms) - with 15 items & 1090.23 & 406.21 & 1051.92 & 309.74 & -0.317 & 0.751 & 0.062 \\
\hline SV $(\mathrm{ms})$ - with 20 items & 1162.61 & 324.10 & 1105.11 & 193.35 & -0.470 & 0.638 & 0.092 \\
\hline ER - total errors & 3.19 & 2.05 & 3.88 & 4.61 & -0.629 & 0.529 & 0.123 \\
\hline RT (ms) - incongruent & 970.61 & 172.81 & 1040.46 & 204.87 & -1.537 & 0.124 & 0.301 \\
\hline RT (ms) - congruent & 869.26 & 158.08 & 949.30 & 161.80 & -1.664 & 0.086 & 0.326 \\
\hline
\end{tabular}

$\mathrm{SV}$ : search velocity; ER: error rate; RT: reaction time; $\mathrm{S}_{\mathrm{ON}}$ : shading-on; $\mathrm{S}_{\mathrm{OFF}}$ shading-off. Note: Correlation is significant for 'Asymp. Sig. (2-tailed)' $<0.1$. 


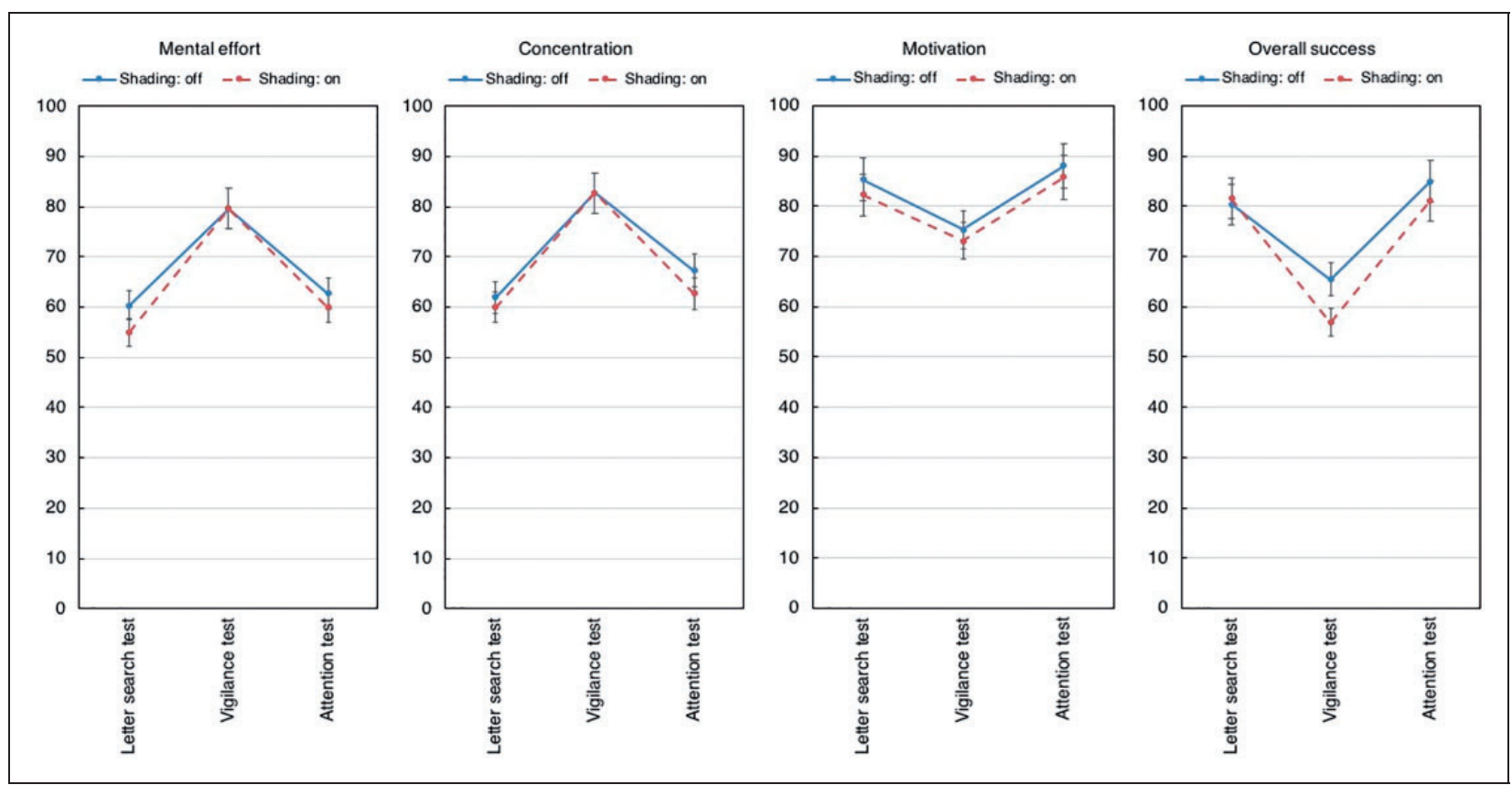

Figure 5. Mean subjective performance scores on letter search, vigilance and sustained attention tests in $\mathrm{S}_{\mathrm{ON}}$ and $\mathrm{S}_{\mathrm{OFF}}$ settings (error bars represent $95 \%$ confidence intervals).

Table 4. Spearman's rho correlation coefficients $(r)$ and $p$-values for significantly correlated GSV ratings and STP indicators.

\begin{tabular}{|c|c|c|c|c|c|c|c|c|}
\hline \multirow[b]{2}{*}{ Task types } & \multicolumn{2}{|c|}{ Overall success - GSV } & \multicolumn{2}{|c|}{ Motivation - GSV } & \multicolumn{2}{|c|}{ Concentration - GSV } & \multicolumn{2}{|c|}{ Mental effort - GSV } \\
\hline & $r$ & $\begin{array}{l}\text { Sig. } \\
\text { (2-tailed) }\end{array}$ & $r$ & $\begin{array}{l}\text { Sig. } \\
\text { (2-tailed) }\end{array}$ & $r$ & $\begin{array}{l}\text { Sig. } \\
\text { (2-tailed) }\end{array}$ & $r$ & $\begin{array}{l}\text { Sig. } \\
\text { (2-tailed) }\end{array}$ \\
\hline Letter search & -0.286 & 0.040 & -0.109 & 0.443 & 0.243 & 0.083 & 0.258 & 0.065 \\
\hline Vigilance & 0.133 & 0.347 & -0.073 & 0.605 & 0.136 & 0.335 & 0.148 & 0.294 \\
\hline Sustained attention & -0.063 & 0.657 & -0.067 & 0.638 & 0.179 & 0.204 & 0.167 & 0.237 \\
\hline
\end{tabular}

Note: Correlation is significant for 'Sig. (2-tailed)' $<0.05$.

GSV: glare sensation vote.

varyingly for all tasks, which somewhat agrees with the argument demonstrating that each type of task requires different amount of cognitive functions.

In a next step, a non-parametric correlation analysis (Spearman's rho) was performed with the GSV scores, in order to assess whether self-reported performance indicators were associated with lower GSV ratings. Indeed, a significant negative correlation was found between the GSV ratings and the replies on overall success questions (see Table 4).

In the letter search task, participants rated themselves to be more successful as they felt more comfortable with the luminous environment. These findings somewhat refer to the positive affect theory of Baron, ${ }^{30}$ which implies that preferred environmental conditions (e.g. lighting in this case) can lead to better performance and higher effort. ${ }^{57}$
Not unexpectedly, self-rated overall score showed significant negative correlations with the ER in vigilance test $(r=-0.320 ; p=0.021)$ and the RT in sustained attention test when stimuli were congruent $(r=-0.301$, $p=0.30)$. Also, statistically significant positive correlations were found between self-rated concentration score and the letter search time in complex stimuli $(r=0.291$; $p=0.36)$ as well as RT in sustained attention test when stimuli were congruent $(r=0.318, p=0.22)$. Participants also reported that they spent more mental effort in congruent stimuli rather than incongruent stimuli during sustained attention test (see Table 5).

Subjective sleepiness. Paired t-test using the data from the KSS evaluations recorded at the beginning and the end of each session was used to compare the self-reported level of alertness. Results indicated that 
Table 5. Spearman's rho correlation coefficients $(r)$ and $p$-values for significantly correlated STP indicators and cognitive task performance variables.

\begin{tabular}{|c|c|c|c|c|c|c|c|c|}
\hline \multirow[b]{2}{*}{ Performance variables } & \multicolumn{2}{|c|}{ Overall success } & \multicolumn{2}{|c|}{ Motivation } & \multicolumn{2}{|c|}{ Concentration } & \multicolumn{2}{|c|}{ Mental effort } \\
\hline & $r$ & $\begin{array}{l}\text { Sig. } \\
\text { (2-tailed) }\end{array}$ & $r$ & $\begin{array}{l}\text { Sig. } \\
\text { (2-tailed) }\end{array}$ & $r$ & $\begin{array}{l}\text { Sig. } \\
\text { (2-tailed) }\end{array}$ & $r$ & $\begin{array}{l}\text { Sig. } \\
\text { (2-tailed) }\end{array}$ \\
\hline SV - with 5 items & -0.006 & 0.968 & -0.259 & 0.063 & -0.146 & 0.300 & -0.029 & 0.836 \\
\hline SV - with 10 items & -0.049 & 0.730 & 0.005 & 0.973 & 0.198 & 0.158 & 0.266 & 0.056 \\
\hline SV - with 15 items & -0.054 & 0.702 & -0.067 & 0.637 & 0.099 & 0.485 & 0.138 & 0.330 \\
\hline SV - with 20 items & -0.249 & 0.074 & 0.073 & 0.606 & 0.291 & 0.036 & 0.221 & 0.115 \\
\hline ER - total errors & -0.320 & 0.021 & -0.030 & 0.833 & 0.268 & 0.055 & 0.196 & 0.163 \\
\hline RT - congruent & -0.301 & 0.030 & -0.124 & 0.382 & 0.318 & 0.022 & 0.337 & 0.014 \\
\hline $\mathrm{RT}$ - incongruent & -0.206 & 0.143 & -0.178 & 0.207 & 0.105 & 0.459 & 0.100 & 0.478 \\
\hline
\end{tabular}

Note: Correlation is significant for 'Sig. (2-tailed)' $<0.05$.

$\mathrm{SV}$ : search velocity; ER: error rate; RT: reaction time.

Table 6. Results from the paired t-test results of subjective alertness.

\begin{tabular}{|c|c|c|c|c|c|c|}
\hline $\mathrm{KSS}_{\mathrm{B}}-\mathrm{KSS}_{\mathrm{E}}$ & $\mathrm{KSS}_{\mathrm{B}}$ & $\mathrm{KSS}_{\mathrm{E}}$ & Mean. Diff. & $\mathrm{t}$ & $\mathrm{df}$ & $\begin{array}{l}\text { Sig. } \\
\text { (2-tailed) }\end{array}$ \\
\hline Overall & 3.5192 & 3.7884 & -0.2692 & -1.044 & 51 & 0.301 \\
\hline Shading: off $\left[\mathrm{S}_{\mathrm{OFF}}\right]$ & 3.3076 & 3.9615 & -0.6538 & -1.799 & 25 & 0.084 \\
\hline Shading: on $\left[\mathrm{S}_{\mathrm{ON}}\right]$ & 3.7307 & 3.6153 & 0.1153 & 0.324 & 25 & 0.749 \\
\hline Morning sample & 3.50 & 3.50 & 0 & 0 & 21 & 1 \\
\hline Afternoon sample & 3.5333 & 4.00 & -0.4666 & -1.239 & 29 & 0.225 \\
\hline
\end{tabular}

$\mathrm{KSS}_{\mathrm{B}}$ : KSS score at the beginning; $\mathrm{KSS}_{\mathrm{E}}$ : KSS score at the end of the session.

Note: Correlation is significant for 'Sig. (2-tailed)' $<0.1$.

Table 7. Spearman's rho correlation coefficients $(r)$ and $p$-values for significantly correlated KSS ratings and STP indicators.

\begin{tabular}{|c|c|c|c|c|c|c|c|c|}
\hline \multirow[b]{2}{*}{ Task types } & \multicolumn{2}{|c|}{ Overall success - KSS } & \multicolumn{2}{|c|}{ Motivation - KSS } & \multicolumn{2}{|c|}{ Concentration - KSS } & \multicolumn{2}{|c|}{ Mental effort - KSS } \\
\hline & $r$ & $\begin{array}{l}\text { Sig. } \\
\text { (2-tailed) }\end{array}$ & $r$ & $\begin{array}{l}\text { Sig. } \\
\text { (2-tailed) }\end{array}$ & $r$ & $\begin{array}{l}\text { Sig. } \\
\text { (2-tailed) }\end{array}$ & $r$ & $\begin{array}{l}\text { Sig. } \\
\text { (2-tailed) }\end{array}$ \\
\hline Letter search & -0.563 & 0.001 & -0.434 & 0.001 & 0.080 & 0.575 & -0.064 & 0.652 \\
\hline Vigilance & -0.254 & 0.069 & -0.313 & 0.024 & 0.008 & 0.953 & -0.043 & 0.761 \\
\hline Sustained attention & -0.190 & 0.176 & -0.444 & 0.001 & -0.061 & 0.668 & -0.047 & 0.743 \\
\hline
\end{tabular}

Note: Correlation is significant for 'Sig. (2-tailed)' $<0.05$; correlation is strong significant for 'Sig. (2-tailed)' $<0.01$.

while the received light level was almost two times more in $\mathrm{S}_{\mathrm{OFF}}$ setting, subjective sleepiness increased over the session $(p<0.1)$, see Table 6 . This finding is surprising and not consistent with most previous research, while in line with a few others indicating that higher illuminance do not necessarily induce alertness specifically in short exposures. Subjective sleepiness (KSS) in $\mathrm{S}_{\mathrm{ON}}$ setting did not differ significantly when comparing KSS-beginning $\left(\mathrm{KSS}_{\mathrm{B}}\right)$ with $\mathrm{KSS}$-end $\left(\mathrm{KSS}_{\mathrm{E}}\right)$ scores $(p=0.749)$ and was $p_{\text {afternoon }}=0.225$ in the afternoon sample, which is relatively close to statistical significance. In the morning data, mean KSS score remained constant $\left(p_{\text {morning }}=1\right)$, which might be explained with higher vitality in the early morning hours. Concerning overall subjective sleepiness ratings including the whole experimental sessions, no significant difference was found between $\mathrm{KSS}_{\mathrm{B}}$ and $\mathrm{KSS}_{\mathrm{E}}(p>0.3)$.

A non-parametric correlation analysis (Spearman's rho) between the KSS ratings and the subjective performance ratings (STP) was performed once again. To this purpose, subjective alertness ratings over the period $\left(\mathrm{KSS}_{\mathrm{B}}\right.$ and $\left.\mathrm{KSS}_{\mathrm{E}}\right)$ were averaged per subject during one experimental session. Results were significant between motivation levels and KSS ratings. Participants rated themselves more motivated in all tasks when their levels of alertness were higher (see 
Table 7). Additionally, a negative correlation $(r=-0.563)$ was obtained between KSS and self-reported overall success in visual search test.

Identical analysis was conducted to examine the correlation between KSS and objective cognitive task performance. Only statistically significant correlation was found between the RT of incongruent trials during sustained attention test and the KSS ratings. The correlation was positive with a value of $r=0.355$, implicating that the RT for incongruent trials was higher when the participants rated themselves sleepier.

\section{Discussion}

The current findings revealed that the use of a shading system improved performance of a VDT user on a task requiring sustained attention, while no significant effects were observed on tasks involving other cognitive skills such as SV and vigilance. One possible explanation might be that, the daylit work environment has a much slighter impact on SV and vigilance than on the performance of a sustained-attention requiring task. Sustained attention might be more sensitive towards variations, even small ones, in the luminous environment. As daylight has a dynamic character, fluctuations in illuminance is inevitable. Although daylight illuminance is within acceptable ranges, in $\mathrm{S}_{\mathrm{ON}}$ setting small variations of the vertical illuminance were shown with respect to the $\mathrm{S}_{\mathrm{OFF}}$ setting (see also Table 1). Except for sustained attention and vigilance test, SV performance of participants became worse under $\mathrm{S}_{\mathrm{ON}}$ setting. This might be a clue to show the triggering effect of dynamic aspect of daylight on such tasks requiring velocity for identifying targets during screen work (which is also quite linked with acute alertness) while other cognitive skills such as vigilance, concentration and attention etc. require less variations and more stability in the illuminance distribution for, e.g. being more focused on such tasks requiring specific demands. These opposite trends in performance are in fact the expression of how optimal illuminances for different brain functions may differ markedly. ${ }^{16}$

In case of time-of-day effects, although there was not any significant performance difference between morning and afternoon samples, within-subjects analysis revealed that morning group performed significantly better on the sustained attention task in $\mathrm{S}_{\mathrm{ON}}$ setting. This result is in line with findings of previous studies suggesting that lower illuminance levels during morning hours promote higher performance in tasks associated with sustained attention. ${ }^{26,27} \mathrm{~S}_{\mathrm{OFF}}$ setting resulted in lower illuminance range and high daylight variation which was two times higher than $\mathrm{S}_{\mathrm{ON}}$ setting. Considering the southeast orientation of workstation receiving morning sunlight more intensely than in the afternoon, therefore, in such cases, the use of solar shading systems can be very useful especially during morning hours for increasing work productivity as well as minimizing accidents in such VDT works requiring high attention.

Another interesting observation of this study was that despite the short practice session before tests for familiarizing participants with the procedure, regardless of the illuminance, better performance on sustained attention test was observed in the second sessions. Similar improvement was not observed on other tasks, yet, this carry over effect should be carefully considered for further studies to minimize the risk of potential confounding factors.

As expected, self-reported glare rates were significantly higher in $\mathrm{S}_{\mathrm{OFF}}$ setting and, moreover, this was more pronounced in the morning sessions $(29 \%$ and $39 \%$, respectively), or perhaps there was a higher tolerance toward the luminous environment during afternoon hours. Besides, in the present study, participants did not have the preference to manipulate the solar shading setting during their experimental sessions, instead, default settings were applied. Yet, a significant correlation between GSV ratings and subjective performance indices was found. Participants rated themselves as more successful in letter search test when their sensation of glare was lower. In a further study, employing a user-set shading strategy in one of the sessions would be a better research practice to explore the relative impact of positive effect. ${ }^{30}$

Regarding the subjective performance indicators, higher illuminance in $\mathrm{S}_{\mathrm{OFF}}$ setting generally appeared to promote more concentration, motivation and mental effort levels during performing tasks. Perhaps by the nature of the awareness, participants' selfreported measures of task performance were significantly correlated with the objective indicators. Within-subjects analysis revealed no statistically significant differences between mean STP values in $S_{\mathrm{ON}}$ and $\mathrm{S}_{\mathrm{OFF}}$ settings.

With respect to subjective measure of alertness, participants reported a lower level of alertness during $\mathrm{S}_{\mathrm{OFF}}$ setting in which there were higher illuminance inside. Despite major differences in material and methods such as the light source and characteristics of the light exposure (intensity, timing, duration etc.), this result is different from what has been found in earlier research and hence, requires a follow-up investigation. Sound associations, on the other hand, were found between alertness and both objective and STP. A significant increase was observed on the level of subjective motivation as well as on RTs in the sustained attention test when participants reported a higher level of alertness. 


\section{Conclusions}

There exists a knowledge gap in the literature, which has not yet allowed a clear determination of the occurrence and direction of light effects on performance, comfort and well-being of individuals under everchanging daylit conditions (where light intensity may vary every second).

The main aim of this study was to evaluate whether the use of an external shading system would have any possible positive effect on cognitive performance, alertness level and visual comfort of individuals in a daylit VDT workstation. In order to pursue this aim, a fullscale mock-up VDT workstation was realized. The mock-up was used, under only daylight conditions, for testing whether cognitive performance, alertness and visual comfort of VDT users changed under two different realistic office daylighting settings, when shadings are active $\left(\mathrm{S}_{\mathrm{ON}}\right)$ and inactive $\left(\mathrm{S}_{\mathrm{OFF}}\right)$. That leads us to notice whether any significant differences might happen when daylight illuminance changes or when daylight variation happens. Findings show that even subtle variations in daylight illuminance range (from around $200 \mathrm{~lx}$ to $2600 \mathrm{~lx}$ at eye level) have remarkable effect on cognitive performance. Sustained attention and some degree of vigilance are found to be positively affected by using shading devices with an average vertical illuminance of $780 \mathrm{~lx}$ in $\mathrm{S}_{\mathrm{ON}}$ setting. Oppositely, performance in SV was prompted by higher illuminance levels of $1300 \mathrm{~lx}$ in $\mathrm{S}_{\mathrm{OFF}}$ setting, although the difference was not significant. The illuminance also had a significant effect on the degree of perceived glare; in $\mathrm{S}_{\mathrm{ON}}$ setting, $780 \mathrm{~lx}$ at eye level promoted more visual comfort than in $\mathrm{S}_{\mathrm{OFF}}$ with $13001 \mathrm{x}$. At most VDT workstations, however, there is an integrated situation between daylight and electric sources. Visual sense holds a different function rather than, e.g. thermal sense and individual variability in lighting preferences has to be taken into consideration for lighting solutions. Future research should incorporate the influence of light sources separately and/or together so as to get a deeper insight into the relationship between the lighting and human performance.

The current findings could provide some supportive evidence to those focused on daylighting design of VDT workplaces, on how to avoid unbalanced illuminance distribution and minimize the occurrence of negative effects while maintaining a high level of task performance and satisfaction. The results from this study pave the way to the future design of daylit workplaces to avoid excessive daylight exposure by using external shading, which can reduce the large variations inherent in daylight. However, more research is needed to validate the findings and to concretely determine the influence of daylighting and its acute non-visual effects on cognitive task performance, visual comfort and alertness in general population of VDT office workers.

\section{Authors' contribution}

All authors contributed equally in the preparation of this manuscript.

\section{Declaration of conflicting interests}

The authors declared no potential conflicts of interest with respect to the research, authorship, and/or publication of this article.

\section{Funding}

The authors received no financial support for the research, authorship, and/or publication of this article.

\section{ORCID iD}

M Öner (D) https://orcid.org/0000-0001-5551-068X

\section{References}

1. Rodriguez RG and Pattini A. Effects of a large area glare source in cognitive efficiency and effectiveness in visual display terminal work. LEUKOS - J Illuminating Eng Soc North Am 2012; 8: 283-299.

2. Leccese F, Salvadori G and Rocca M. Visual discomfort among university students who use CAD workstations. WOR 2016; 55: 171-180.

3. Leccese F, Salvadori G and Rocca M. Visual ergonomics of video-display-terminal workstations: field measurements of luminance for various display settings. Displays 2016; 42: 9-18.

4. Bisegna F, Burattini C, Li Rosi O, Blaso L and Fumagalli S. Non visual effects of light: an overview and an Italian experience. Energy Proc 2015; 78: 723-728.

5. Sundstrom ED. Work Places: The psychology of the physical environment in offices and factories. Cambridge, New York: Cambridge University Press, 1986.

6. Burattini C, Piccardi L, Curcio G, Ferlazzo F, Giannini AM and Bisegna F. Cold LED lighting affects visual but not acoustic vigilance. Build Environ 2019; 151: 148-155.

7. Curcio G, Piccardi L, Ferlazzo F, Giannini AM, Burattini $\mathrm{C}$ and Bisegna $\mathrm{F}$. LED lighting effect on sleep, sleepiness, mood and vigor. In: Proceedings of 16th IEEE international conference on environment and electrical engineering, Firenze, Italy, June 7-10 2016; pp.1-5.

8. Van Bommel W and Van Den Beld G. Lighting for work: a review of visual and biological effects. Light Res Technol 2004; 36: 255-269.

9. Grieco A and Molteni G. Seating and Posture in VDT Work. In: W Karwowski and WS Marras (eds) The occupational ergonomics handbook. Baca Raton, FL: CRC Press, 1999, pp.1779-1791.

10. Leccese F, Salvadori G, Montagnani C, Ciconi A and Rocca M. Lighting assessment of ergonomic workstation 
for radio diagnostic reporting. Int J Ind Ergon 2017; 57: 42-54.

11. Kunduraci AC, Kazanasmaz $\mathrm{T}$ and Hordijk T. Examining occupancy and architectural aspects affecting manual lighting control behavior in offices based on a user survey. Light Eng 2018; 26: 139-147.

12. Smolders K. Daytime light exposure e effects and preferences. Doctoral dissertation, Eindhoven University of Technology, Eindhoven, the Netherlands, 2013.

13. Oweikeye J, Amasuomo M and Alio AN. Students' perception of daylight illumination in the school workshop as a determinant for effective students' task performance in workshop practice. J Educ Learn 2013; 2: 201-207.

14. Phipps-Nelson J, Redman JR, Dijk DJ and Rajaratnam SM. Daytime exposure to bright light, as compared to dim light, decreases sleepiness and improves psychomotor vigilance performance. Sleep 2003; 26: 695-700.

15. Smolders K, De Kort YAV and Cluitmans P. A higher illuminance induces alertness even during office hours: findings on subjective measures, task performance and heart rate measures. Physiol Behav 2012; 107: 7-16.

16. Sun $C$, Lian $Z$ and Lan L. Work performance in relation to lighting environment in office buildings. Indoor Built Environ. Epub ahead of print 26 December 2018. https://doi.org/10. 1177/1420326X18820089.

17. Huiberts LM, Smolders K, IJsselsteijn WA and de Kort YAW. Shining light on memory: The effects of daytime bright light exposure on memory task performance varying in difficulty level. In: Proceedings of experiencing light 2014: international conference on the effects of light on wellbeing, Eindhoven, the Netherlands, November 10-11 2014; pp.44-47.

18. Fostervold K and Nersveen J. Proportions of direct and indirect indoor lighting - the effect on health, well-being and cognitive performance of office workers. Light Res Technol 2008; 40: 175-200.

19. Eklund NH, Boyce PR and Simpson SN. Lighting and sustained performance. J Illuminating Eng Soc 2000; 29: 116-130.

20. Knez I. Effects of indoor lighting on mood and cognition. J Environ Psychol 1995; 15: 39-51.

21. Salvadori G, Leccese F, Burattini $C$ and Bisegna F. Photobiological and circadian effects of LED displays: comparison between different laptop configurations. In: Proceedings of 18th IEEE international conference on environment and electrical engineering, Palermo, Italy, June 12-15 2018; pp.1864-1869.

22. Cuttle C. People and windows in workplaces. In: Proceedings of the people and physical environment research conference, Wellington, New Zealand, June 8-11 1983; pp.203-212.

23. Heerwagen JH and Heerwagen DR. Lighting and psychological comfort. Light Des Appl 1986; 16: 47-51.

24. Veitch JA, Hine DW and Gifford R. End users' knowledge, preferences, and beliefs for lighting. J Interior Des 1993; 19: 15-26.

25. Veitch JA and Gifford R. Assessing beliefs about lighting effects on health, performance, mood and social behavior. Environ Behav 1996; 28: 446-470.
26. Rodriguez RG, Yamín Garretón JA and Pattini AE. Glare and cognitive performance in screen work in the presence of sunlight. Light Res Technol 2016; 48: 221-238.

27. Gou Z, Lau SS and Qian F. Comparison of mood and task performance in naturally-lit and artificially-lit environments. Indoor Built Environ 2015; 24: 27-36.

28. Ochoa CE and Capeluto IG. Evaluating visual comfort and performance of three natural lighting systems for deep office buildings in highly luminous climates. Build Environ 2006; 41: 1128-1135.

29. Bellia L, Fragliasso F and Stefanizzi E. Daylit offices: a comparison between measured parameters assessing light quality and users' opinions. Build Environ 2017; 113: 92-106.

30. Baron RA. Environmentally induced positive affect: its impact on self-efficacy, task performance, negotiation, and conflict. J Appl Social Pyschol 1990; 20: 368-384.

31. Baron RA and Thomley J. A whiff of reality: positive affect as a potential mediator of the effects of pleasant fragrances on task performance and helping. Environ Behav 1994; 26: 766-784.

32. Knez I and Enmarker I. Effects of office lighting on mood and cognitive performance and a gender effect in work-related judgment. Environ Behav 1998; 30: 553-567.

33. Casey MB. Gender, sex, and cognition: considering the interrelationship between biological and environmental factors. Learn Individual Diff 1996; 8: 39-53.

34. Hyde JS. Sex and cognition: gender and cognitive functions. Curr Opin Neurobiol 2016; 38: 53-56.

35. Knez I and Kerz C. Effects of indoor lighting, gender, and age on mood and cognitive performance. Environ Behav 2000; 32: 817-831.

36. Monteoliva JM, Rodriguez RG, Pattini AE and Ison MS. Daylighting and cognition: experimental studies on working memory and attention in clerical and educational contexts. In: Proceedings of EXPERIENCING LIGHT 2012: international conference on the effects of light on wellbeing, Eindhoven, the Netherlands, November 12-13 2012; pp.1-4.

37. Guillemette J, Hébert $\mathrm{M}$, Paquet $\mathrm{J}$ and Dumont $\mathrm{M}$. Natural bright light exposure in the summer and winter in subjects with and without complaints of seasonal mood variations. Biol Psychiatry 1998; 44: 622-628.

38. Huiberts LM and Smolders Kchj De Kort Y. Seasonal and time-of-day variations in acute non-image forming effects of illuminance level on performance, physiology, and subjective well-being. Chronobiol Int 2017; 34: $827-844$.

39. Commission Internationale de l'Eclairage. Ocular lighting effects on human physiology and behaviour. No. CIE 158:2004. Vienna, Austria: CIE, 2004.

40. Fortuin G. Visual power and visibility. Philips Res Rep 1951; 6: 347-371.

41. Roenneberg T, Wirz-Justice A and Merrow M. Life between clocks: daily temporal patterns of human chronotypes. J Biol Rhythms 2003; 18: 80-90.

42. ISO/CIE 19476:2014. Characterization of the performance of illuminance meters and luminance meters. Geneva, 
Switzerland: International Organization for Standardization (ISO), 2014.

43. Mackworth NH. The breakdown of vigilance during prolonged visual search. $Q J$ Exp Psychol 1948; 1: 6-21.

44. Lichstein KL, Riedel BW and Richman SL. The Mackworth clock test: a computerized version. J Psychol 2000; 134: 153-161.

45. Parkin BL, Warriner K and Walsh V. Gunslingers, poker players, and chickens 1: decision making under physical performance pressure in elite athletes. Progr Brain Res 2017; 234: 291-316.

46. Veitch JA. Flicker effects on brain activity. Light Des Appl 2013; 43: 56-59.

47. Stoet G. PsyToolkit - a software package for programming psychological experiments using Linux. Behav Res Meth 2010; 42: 1096-1104.

48. Stoet G. PsyToolkit: a novel web-based method for running online questionnaires and reaction-time experiments. Teach Psychol 2017; 44: 24-31.

49. Åkerstedt $\mathrm{T}$ and Gillberg M. Subjective and objective sleepiness in the active individual. Int J Neurosci 1990; 52: 29-37.

50. Huiberts LM, Smolders K and de Kort Y. Shining light on memory: effects of bright light on working memory performance. Behav Brain Res 2015; 294: 234-245.
51. Hopkinson RG. The multiple criterion technique of subjective appraisal. $Q J$ Exp Psychol 1950; 2: 124-131.

52. Fisher RA. Statistical methods for research workers. In: S Kotz and NL Johnson (eds) Breakthroughs in statistics. Springer series in statistics (perspectives in statistics). New York, NY: Springer, 1992, pp.66-70.

53. Chraibi S, Lashina T, Shrubsole P, Aries M, Van Loenen E and Rosemann A. Satisfying light conditions: a field study on perception of consensus light in Dutch open office environments. Build Environ 2016; 105: 116-127.

54. Field A. Discovering statistics using IBM SPSS statistics. 4th ed. London: Sage, 2013.

55. Ferguson CJ. An effect size primer: a guide for clinicians and researchers. Profession Psychol: Res Pract 2009; 40: 532-538.

56. Kent MG, Altomonte S, Tregenza PR and Wilson R. Discomfort glare and time of day. Light Res Technol 2015; 47: 641-657.

57. Veitch JA. Lighting for high-quality workplaces. Creating the productive workplace. London, UK: Taylor \& Francis, 2006. 